\title{
Association of spina bifida with cancer
}

\author{
Angela M. Arlen ${ }^{1}$, Anne G. Dudley ${ }^{2,3}$, Kathleen Kieran ${ }^{4,5}$ \\ ${ }^{1}$ Department of Urology, Yale University School of Medicine, New Haven, CT, USA; ${ }^{2}$ Division of Urology, Connecticut Children's Medical Center, \\ Hartford, CT, USA; ${ }^{3}$ Department of Urology, University of Connecticut School of Medicine, Farmington, CT, USA; ${ }^{4}$ Division of Urology, Seattle \\ Children's Hospital, Seattle, WA, USA; ${ }^{5}$ Department of Urology, University of Washington, Seattle, WA, USA \\ Contributions: (I) Conception and design: All authors; (II) Administrative support: None; (III) Provision of study materials or patients: All authors; \\ (IV) Collection and assembly of data: All authors; (V) Data analysis and interpretation: All authors; (VI) Manuscript writing: All authors; (VII) Final \\ approval of manuscript: All authors. \\ Correspondence to: Kathleen Kieran, MD, MSc, MME. Division of Urology, Seattle Children's Hospital, 4800 Sand Point Way NE, OA.9.220, Seattle, \\ WA 98105, USA. Email: kathleen.kieran@seattlechildrens.org.
}

\begin{abstract}
While the worldwide incidence of newborns with spinal dysraphism is decreasing, the majority of children now survive and reach adulthood, creating new challenges in patient management and long-term care. Despite medical and surgical advances with a subsequent decline in mortality, spina bifida continues to be a major cause of chronic disability and affected individuals face increased mortality in adulthood. The majority of spina bifida patients have neurogenic bladder. Reconstructive and diverting procedures may increase the neoplastic risk in the urinary tract over time, however bladder dysfunction itself may be a risk factor, therefore patients, caregivers, and physicians must be aware of the baseline risk of cancer in patients with neurogenic bladder, in addition to routine cancer screening. Optimal treatment of myelomeningocele requires a multidisciplinary care team to prevent and manage potential sequelae that may affect function, quality of life, and survival.
\end{abstract}

Keywords: Spina bifida; myelomeningocele; neurogenic; cancer; neoplasm; transition; reconstruction

Submitted Nov 21, 2019. Accepted for publication Apr 21, 2020.

doi: 10.21037/tau-19-771

View this article at: http://dx.doi.org/10.21037/tau-19-771

\section{Introduction}

Spina bifida is a congenital anomaly characterized by protrusion of the spinal cord and/or meninges through a vertebral bony defect. It is the most common neural tube defect, occurring in approximately 1 out of every 3,000 live births (1). Although the incidence of spina bifida significantly decreased after introduction of mandatory fortification of enriched grain products with folic acid in the United States, the population burden of spina bifida continues both in birth prevalence and in disparate longterm outcomes $(2,3)$. There is variable impact on somatic, parasympathetic and sympathetic innervation of the detrusor and sphincteric muscles, that affects the bladder's ability to store and empty urine. Poor bladder dynamics can lead to chronic kidney disease and a multitude of potential sequelae (4). Myelomeningocele is almost always associated with neurogenic bladder, thus urologic issues are a significant source of morbidity and mortality throughout life. Management of neurogenic bladder includes achieving low pressure urinary storage and providing urinary continence while preserving upper tract function. Bladder augmentation is a frequent component in attaining these goals in patients who have failed medical management, but its utility can be limited by substantial morbidity including increased neoplastic risk. Adult patients with spina bifida have been shown to have an increased risk of mortality, with sepsis, heart or kidney failure, as well as neoplasms, contributing to most deaths (5). As more individuals with spina bifida are reaching adulthood, understanding age and condition-specific risks and implementation of better screening and treatment strategies for known causes of morbidity and mortality, including malignancy, is crucial. The purpose of this review is to summarize the available 
literature regarding recommendations for general cancer screening as well as to review lower urinary tract malignancy in patients with spina bifida.

\section{Background}

Spina bifida is the most common nonchromosomal birth defect in the United States resulting in severe disability of multiple organ systems, and can be associated with motor, sensory and cognitive impairments $(6,7)$. Survival has increased due to significant advances in treatment of associated conditions, such as hydrocephalous and neurogenic bladder (8). As many as $85 \%$ of children with spina bifida are now reaching adulthood, with $67 \%$ of the spina bifida population now comprised of adults (9-11). Increased longevity of patients with spina bifida has led to a paradigm shift in management, as adults with spina bifida present new challenges.

The majority of spina bifida specialty care centers are found in comprehensive pediatric multidisciplinary hospital or clinical settings. Few comprehensive adult care centers exist, resulting in less access to specialists (9). Patients with spina bifida experience various barriers during their transition into adult-centered health care, with poor outcomes exacerbated by lack of intellectual and/ or physical capacity to independently perform self-care and navigate the healthcare system (12-14). Urinary tract infections, complications from devices such as shunts and bladder catheters, and skin wounds are the most common reasons for hospitalization in adult spina bifida patients, and approximately one-third of hospitalizations are due to potentially preventable conditions (15). Furthermore, adults with spina bifida face unique health challenges, such as an increased risk of malignancy-related mortality compared to age-matched peers (5). Many of these conditions are potentially predictable and preventable, and effective early interventions may significantly reduce patient morbidity (16). The health care system has been relatively slow to respond to the need for multidisciplinary care among adults with spina bifida, leading to unanswered questions about preventive care including intrinsic malignancy risk, potential sequelae of bladder management/augmentation and screening considerations.

\section{Screening for malignancy}

While previously regarded as a pediatric condition, twothirds of patients with spina bifida are now adults, and at risk for a host of medical conditions, including development of malignancy (17). Several factors may impact presentation, diagnosis and treatment outcomes that are specific to individuals with spina bifida. First, medical care may be fragmented. Multidisciplinary care delivery is standard in pediatric programs, however there is limited access to coordinated specialists in the adult realm $(18,19)$. Disjointed care places the onus for coordination on the primary care provider; however, individuals with spina bifida may have difficulty accessing appropriate primary care (17). In a Canadian survey of patients with congenital conditions including spina bifida regarding care utilization, outpatient health care utilization was high (1.0 visit per person/ month), however most individuals did not actually have a primary care physician (20). This has strong implications on preventative care, as screening is most often managed by the primary physician (17). In a study of patients with disability, women were $17 \%$ less likely to undergo Papanicolaou testing and $13 \%$ less likely to undergo mammogram compared with the general population, a pattern mimicked in men, who were $19 \%$ less likely to undergo PSA testing (21). Clinical attention may be focused on comorbid conditions such as headaches, shunt dysfunction, orthopedic concerns or pain, rather than preventative measures. Many individuals may have long term risk factors from childhood and infancy; including bacteriuria from intermittent or indwelling catheterization, ionizing radiation exposure for a wide range of comorbid conditions. Patients with renal failure requiring transplantation are often on immunosuppressive medications. Lastly, non-ambulatory status may lead to incomplete examination of certain body areas, such as skin, pelvic and areas under braces. This may be further limited by medical facilities with examination tables without ability to lower, ability of patients to self-transfer, and or lack of lifts and/or staff. In patients with contractures or significant scoliosis, modified positioning for physical examinations may provide suboptimal access and require alternate methods as discussed below.

Spina bifida patients are at risk for medical conditions that may also impact malignancy risk. For example, obesity may increase risk of certain malignancies such as renal, endometrial, esophageal, colorectal, breast, and prostate cancers (22). The incidence of obesity in patients with spina bifida has been reported to be as high as $35 \%$, depending on method used to classify obesity (23). Ongoing efforts to appropriately risk stratify patients have led to use of dual energy X-ray absorptiometry (DXA) measurements of truncal fat and abdominal circumference, 
which may be more reliable than standard body mass index due to different body habitus in spina bifida (23). The role of mental health conditions such as anxiety and depression on ability to seek care for concerning physical self-exam findings should not be underestimated. Delay in seeking care due to anxiety and depression has been noted, and outcomes for many malignancies remain poorer in those with mental health conditions such as depression, independent of cancer stage (24). In addition to mental health concerns, cognitive impairment is noted in a subset of individuals with spina bifida, more frequently in those with hydrocephalus (25). As the patient becomes a young adult, their transitional care is often overseen by parental caregivers or guardians (26). As caregivers age, the patient's limited ability to manage his or her own complex medical needs presents an ongoing challenge.

Presently, there are limited data regarding prevalence, stage at diagnosis and outcomes of malignancy in the spina bifida population, with the exception of bladder cancer, which is discussed in detail below. Principles such as prompt diagnosis and workup should guide evaluation for possible malignancy, and treatment should be initiated in a timely manner once detected.

Conditions specific to men's health may be a challenge for the adult spina bifida population, as men are less frequent users of the healthcare system after transition compared with women $(19,26)$ Testicular cancer is most commonly diagnosed in young adults and adolescents. Men with spina bifida have increased risk of cryptorchidism, likely due to decreased abdominal pressure, from lax muscle tone of the abdominal wall. Ferrara and colleagues reported a $14.6 \%$ incidence of undescended testes in the meningomyelocele population, with $72 \%$ of patients having bilateral cryptorchidism (27). There is a reported association between spina bifida occulta and increased risk of testicular cancer, though the data are limited for myelomeningocele patients (27-29). The rate of ascended testes in this population is unknown, but yearly examination is needed to ensure orthotopic position. While no data exist specific to the spina bifida population, it is likely that timely orchiopexy would reduce malignancy risk, yet males with spina bifida are at risk for diagnostic delay (29). Routine genital exams may not be reliably performed in men, especially those who are non-ambulatory in the community, and palpable masses could be missed. In patients with higher lesion levels and limited genital sensation, pain and discomfort may be absent, possibly delaying presentation as well. Further study into testicular cancer outcomes is needed to ensure that patients with spina bifida achieve outcomes comparable to the general population.

Prostate cancer is diagnosed in males with spina bifida, as it is the second most common malignancy in men in the United States (30,31). Recently, the US Preventative Services Task Force recommended against routine prostate specific antigen screening (31). At present, there is a focus on appropriate detection of clinically significant disease, utilization of active surveillance, and active treatment of those at highest risk. The American Cancer Society (ACS) recommends shared decision making in men with a 10 -year life expectancy, to determine if PSA/DRE screening is appropriate at age 45-50 depending on risk factors (31). AUA Guidelines recommend shared decision making for men age 55-69, and risk factor-based decisions for higher risk patients (32). PSA has historically been combined with digital rectal examination to determine if an at-risk patient may benefit from prostate biopsy. DRE and prostate biopsy may be challenging due to contractures in patients with spina bifida, however MRI fusion is increasingly utilized. Perineal biopsy is a useful alternative with appropriate cancer detection (33). In patients with baseline neuropathic bladder, dependent on intermittent catheterization for bladder emptying, PSA kinetics can vary. Several studies have attempted to report expected values for age for men on intermittent catheterization, without consensus (34): one study reported doubling of PSA values, whereas others did not detect a difference compared with controls (14,34). The role of colonization and bacteriuria has important implications for patients undergoing TRUS biopsy, and perineal biopsy may limit infectious concerns but is not widely performed. Screening remains important in patients with spina bifida with at least ten years of life expectancy, as early detection may allow for improved outcomes. Limited data is available regarding prostate cancer in men with spina bifida, but a recent report does highlight higher costs and length of stay during inpatient hospitalization (30) Men with spinal cord injuries and prostate cancer have previously reported higher stage, with $63.9 \%$ T3 or metastatic at diagnosis, compared with men without spinal cord injuries (35).

Breast and cervical cancer occur in women with myelomeningocele, although there are limited data comparing the incidence of these malignancies to the general population. Breast cancer is the most commonly diagnosed malignancy in women (31). Individuals with spina bifida should follow recommendations personalized to risk level, as published by the ACS, with mammograms 
starting at age 45 or sooner based on risk factors. Little evidence exists regarding breast cancer in individuals with spina bifida, including lack of reported adherence to mammography guidelines and stage at diagnosis. Underlying comorbid conditions such as incontinence, or even dexterity may be exacerbated by treatment. One case report described urinary and fecal incontinence as well as peripheral neuropathy which impacted dexterity for catheterization, all of which worsened after chemotherapy for breast malignancy (36).

Cervical cancer has decreased in incidence with the introduction of regular screening as well as human papilloma virus vaccine, as sexually transmitted HPV infection may lead to cervical intraepithelial neoplasia and cervical cancer (37). Despite the vaccine's early success, continued screening is needed (37). At present, no studies report spina bifidaspecific outcomes, but regular screening starting at age 21 , as recommended by ACS, is highly recommended (31). Individuals with spina bifida may have had little education regarding sexual health and the risks of sexual activity $(27,38,39)$. Additionally, latex sensitivity in this population may require use of protection in non-latex form (sheepskin, polyurethane, polyisoprene). Sheepskin does not offer the same protection against STI as latex condoms, possibly increasing risk of HPV and penile cancer (40). As previously noted, patients with myelomeningocele have higher health care utilization than their healthy peers, but disproportionately seek care in urgent or emergent settings. Previous work has demonstrated lower rate of screening compliance for cervical, breast and prostate cancer in patients with patients with disability (21). Further study is needed in this population, to determine outcomes of cervical cancer and pre-malignant lesions. In coming years, vaccination with continued screening could further reduce the burden of cervical cancer (37).

Presently, vaginal and vulvar malignancies do not have specific screening recommendations yet individuals with spina bifida remain at risk just as general population. Of note, a case of vaginal tubulovillous adenoma was reported in a teenager with myelomeningocele, presenting with irregular vaginal bleeding after suburethral sling (41). Endometrial cancer is typically diagnosed in older, usually post-menopausal, women, with increasing risk with obesity, nulliparity and early menarche. This may be of concern given increased longevity in women with spina bifida. ACS recommends screening for endometrial cancer only for very high-risk patients (Lynch syndrome, autosomal dominant colon cancer susceptibility) (31). In average-risk women, symptoms such as irregular bleeding should be promptly investigated.

Lung cancer remains highly morbid in both men and women, and is the leading cause of malignancy-related death in the United States (31). Shared decision making between patient and physician is the basis for screening with low-dose CT scan. Screening is recommended in adults 55-74 years of age who meet specific patient factors including a 30+ pack-year history of smoking (31). Though no literature currently exists to suggest individuals with spina bifida are at an increased risk for primary lung cancer, individuals with spina bifida may have scoliosis and limited lung fields at baseline, and as such, imaging may be more difficult to interpret but previous images within a system are often available to compare.

Other common malignancies in the general population include colorectal cancer, which has been decreasing in incidence due to screening. General recommendations include screening via high sensitivity stool testing and/ or endoscopy at age 45-50 depending on risk factors (31). Risk factors relevant to individuals with spina bifida include sedentary lifestyle, obesity and possibly dietary choices (28). Symptoms concerning for malignancy such as hematochezia should be investigated, though nonspecific abdominal pain may be less likely given sensory deficits in myelomeningocele. Colonic resection has been utilized in some patients for refractory neuropathic bowel and resected segments should be examined thoroughly for polyps or premalignant changes (42).

With respect to urologic malignancies, the primary focus is on bladder cancer, discussed below. Other urologic malignancies such as renal cell carcinoma may be present at increased rates due to obesity risk in the spina bifida population, but no large-scale studies are presently available. Renal and urothelial cell carcinomas may present with hematuria, which is not uncommon in patients on catheterization regimens, and so a high index of suspicion must be maintained, particularly in patients with persistent hematuria. AUA guidelines for hematuria do not give specific recommendations in the setting of neuropathic bladder, or with baseline catheterization (43).

\section{Radiation-induced malignancy}

Patients with spinal dysraphism are exposed to numerous radiographic studies throughout their life-studies that employ ionizing radiation are an essential tool for the evaluation of children with neural tube defects. Spina bifida 
Table 1 Approximate radiation dose from common radiology studies

\begin{tabular}{lc}
\hline Imaging & $\begin{array}{c}\text { Approximate effective radiation } \\
\text { dose (adults) }\end{array}$ \\
\hline CT abdomen/pelvis & $10 \mathrm{mSv}$ \\
CT A/P w/wo contrast & $20 \mathrm{mSv}$ \\
Barium enema & $8 \mathrm{mSv}$ \\
Upper Gl study & $6 \mathrm{mSv}$ \\
Spine X-ray & $1.5 \mathrm{mSv}$ \\
Chest X-ray & $0.1 \mathrm{mSv}$ \\
Foot X-ray & $0.001 \mathrm{mSv}$ \\
CT head & $2 \mathrm{mSv}$ \\
CT head w/wo contrast & $4 \mathrm{mSv}$ \\
CT spine & $6 \mathrm{mSv}$ \\
\hline
\end{tabular}

patients often have surveillance neuroimaging, i.e., multiple brain CT scans to assess for associated Arnold-Chiari II malformation and hydrocephalus, and to evaluate function of ventriculoperitoneal shunts, if present. They also undergo periodic bladder assessment with videourodynamic studies and voiding cystourethrograms. In addition, they routinely undergo various plain films to evaluate orthopedic issues such as spinal curvature and hip subluxation. Thus, the spina bifida cohort is very likely to have a much greater exposure to radiation than the average person during childhood (44).

It is well established that exposure to radiation introduces a risk of malignancy based on cumulative effective dose, with risk for exposures exceeding 50 milliSievert $(\mathrm{mSv})$ derived primarily from the Life Span Study (45). For a given dose, there is a difference in cancer risk from radiation exposure to children compared with adults, as tissues and organs that are growing and developing are more sensitive to radiation effects than those that are fully mature. In addition, the oncogenic effect of radiation may have a long latent period so an infant or child has a longer life expectancy in which to manifest the potential oncogenic effects of radiation compared with older adults (45-47). The effective radiation dose for several common imaging studies are detailed in Table 1; it should be noted this dosing is for the average-sized adult and doses vary significantly for pediatric patients. Protocols utilized during imaging such as computed tomography are additional sources of radiation, and must be adjusted for patient age and size to ensure optimal imaging quality and minimize radiation exposure.

In 2012, the first large-scale study was published demonstrating evidence of increased risk of secondary malignancy in children from medical imaging; this landmark study showed significant increases in leukemia incidence in pediatric patients with cumulative bone marrow doses of $30 \mathrm{mSv}$, and significant brain tumor incidence in children with brain doses of at least $50 \mathrm{mSv}$ (48). A study by van Aalst et al. reported a mean childhood dose of $23 \mathrm{mSv}$ in patients with spina bifida, resulting in an additional $0.37 \%$ lifetime risk of cancer (49). However, other groups have reported a much higher, and thus concerning, mean cumulative effective dose of $81.9 \mathrm{mSv}$ ( $2.6 \mathrm{mSv} /$ patient/year over 18 years $)$ in spina bifida patients with hydrocephalus (50).

Clinicians must recognize that increased radiation exposure with studies ordered by various specialties, puts patients with spina bifida at greater risk for malignancy, particularly when hydrocephalus is present, given the increased number of ionizing studies these patients accumulate over time. Adherence to the "as low as reasonably achievable" (ALARA) and Image Gently principles helps to minimize radiation exposure while still obtaining high quality images $(51,52)$. Radiologists should be utilized to help determine optimal imaging modalities, limit ionizing radiation and minimize repeat imaging when clinically appropriate (48). Need for surveillance of radiation-related malignancy is dependent upon a given patient's total cumulative effective dose-which highlights the need to be cognizant of the number of ionizing studies obtained.

\section{Lower urinary tract malignancy}

Lower urinary tract management has afforded children with spina bifida improved continence, better protection of the upper urinary tracts, prolonged survival, and increased independence and quality of life. However, some reconstructive and diverting procedures will increase the neoplastic risk in the urinary tract; in many cases, these cancer risks are not immediate, making it critical for surgeons to prospectively counsel parents and children regarding known risks and the potential development of new risks. Patients, caregivers, and physicians must also be aware of the baseline risk of cancer in patients with neurogenic bladder and the need for close monitoring even in the absence of surgery.

\section{Risks associated with urinary diversion and reconstruction}

Increased risk of neoplasia associated with prolonged 
exposure of gastrointestinal mucosa to urine has been known for decades. Concerns about neoplasia in patients with diversions and reconstructions arose because of ureterosigmoidostomy. This procedure, in which the ureters drain into the sigmoid colon, is associated with a $11-24 \%$ cumulative risk of adenocarcinoma, compared with an about $4.2 \%$ lifetime risk of colon cancer in the general population (53-57). These tumors typically arise at the anastomosis of the distal ureter with the sigmoid colon and are believed to arise in the setting of increased nitrosamine produced by colonic bacteria exposed to urine components (58). Given the well-documented neoplastic risk, ureterosigmoidostomy has fallen out of favor except in carefully selected patients, and in particular is avoided in patients with benign indications for urinary diversion. Patients with ureterosigmoidostomies (or similar procedures such as the Mainz II or Atta pouches) should be evaluated annually with sigmoidoscopy, beginning 10 years after surgery $(59,60)$. Routine biopsy is not recommended. Even if patients with ureterosigmoidostomy are converted to an alternate form of urinary diversion, annual sigmoidoscopy is recommended if there is not clear evidence that the ureterosigmoid anastomoses have been entirely resected (61). Although serum carcinoembryonic antigen (CEA) levels are increased in patients with rectal diversions, these elevations are not reliable indicators of neoplasia and thus CEA is not suitable for screening (62).

In part because of the oncologic risks associated with ureterosigmoidostomy, augmentation cystoplasty (wherein the urinary reservoir volume is increased by adding a patch of bowel to the native bladder) is currently the preferred surgical option for patients with small, poorly compliant bladders. While ileum and sigmoid colon are the most commonly used bowel segments for augmentation, gastrocystoplasty was a popular procedure at one point, particularly for children with renal failure and resultant metabolic acidosis (63). Like ureterosigmoidostomy, it is now rarely performed, however clinicians should be aware of the late effects associated with gastrocystoplasty.

Although augmentation cystoplasty has classically been considered a risk factor for neoplastic transformation in the urinary reservoir, more recent work has suggested that oncogenesis in the spina bifida population is likely multifactorial, reflecting a complex interaction of risk factors rather than the sequela of a single surgical procedure. Rove et al. performed a systematic review of manuscripts discussing spina bifida and malignancy and found that neoplasia developed in $2-4 \%$ of spina bifida patients; while nearly three-quarters of patients had locally advanced or metastatic disease, overall survival was similar in patients with and without augmentation cystoplasty (64). A retrospective review of 385 patients at a single institution with a median follow-up of 26 years found $4 \%$ of patients with ileal or colonic augmentation cystoplasty developed bladder cancer, compared with $2.5 \%$ of age-matched controls. While the authors concluded that this difference was not statistically significant, it should be noted that other risk factors (e.g., smoking) were not considered in this analysis. Patients who developed bladder tumors did so decades after the augmentation cystoplasty, with the earliest tumor developing 22 years after surgery and the longest latency 51 years. Pathology showed adenocarcinoma in three-quarters of patients and transitional cell carcinoma in the remaining $25 \%$ (65).

Multiple factors, including the time since surgery, the choice and length of gastrointestinal segment utilized for augmentation, historical viruria, and prolonged immunosuppressive use, are all associated with increased risk of neoplasia following augmentation cystoplasty. Use of gastric segments is associated with the highest risk of neoplastic transformation following augmentation cystoplasty. One retrospective study in a single center performing a large number of gastrocystoplasties found that $2.8 \%$ (two) of 72 patients developed adenocarcinoma a median of 14 years following gastrocystoplasty. Perhaps more remarkable was that both patients had widely metastatic disease at diagnosis (66). Compared with patients undergoing augmentation cystoplasty with other bowel segments, the earlier presentation and more extensive disease in this population raises concern that gastrocystoplasty may be associated with a more aggressive, earlier-onset variant of neoplasm that may be missed by clinicians without a high index of suspicion. Comparable results were reported by a French group, where three of 11 patients with gastrocystoplasty developed adenocarcinoma, a median of two decades following augmentation. Two of these patients had metastatic disease at diagnosis. Importantly, seven of the 11 patients underwent removal of the gastric patch a median of 11 years after augmentation (67). A similar rate of neoplasia was reported by Castellan et al., who found that three of 29 patients developed cancer in bladders augmented with gastric segments, and all died of metastatic disease (68). Conversely, a twenty-two-year single institution review of patients with cloacal exstrophy undergoing gastrocystoplasty found no neoplasia at a 13year median follow-up (69). 


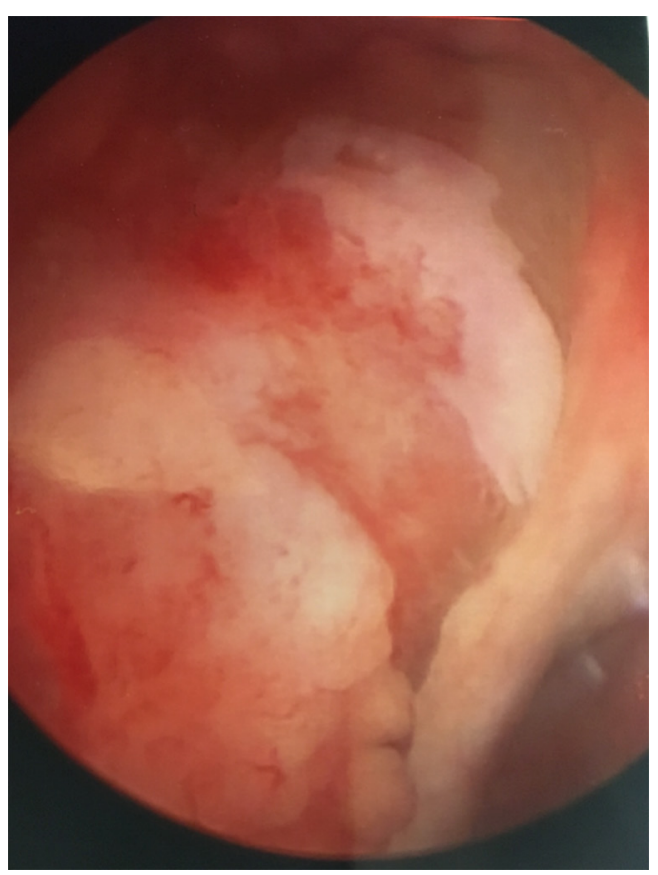

Figure 1 Neoplastic mass within a bladder augmented with colon. Image courtesy of Jane L. Miller, MD.

While the mechanisms underlying neoplastic transformation following augmentation cystoplasty are not well known, histologic changes in cells at the anastomosis of the bowel and bladder have been reported in this setting (70,71). "Intestinalization," or the development of histologic findings typical of bowel in the native bladder following augmentation, has also been reported (72). In the past, common practice was to perform annual evaluation not only of the augmented reservoir (73) but also of catheterizable channels, since neoplasia has been reported in an appendicovesicostomy (74). Urine cytology was often collected as well, though its accuracy is greatest for the detection of transitional cell carcinomas, which are relatively underrepresented in the population of patients who develop cancer in a neurogenic bladder. More recent data have suggested that annual surveillance is not necessary nor is it cost-effective in asymptomatic patients (75). In one retrospective series of patients with colonic and ileal augmentation cystoplasty undergoing annual endoscopic screening found that all had negative cytology and only four had bladder lesions: one adenomatous polyp, one squamous metaplasia, and two nephrogenic adenomas. The absence of clinical findings suggestive of neoplasm led the authors to stop annual endoscopy after five years; patients were followed for an additional decade with none developing neoplasia in the augmented bladder (76). Szymanski and colleagues had similar findings in a cohort of 413 patients followed for two decades, of whom none developed malignancy after augmentation cystoplasty ( $81 \%$ were augmented with ileum) (77).

Husmann points out that universal endoscopic screening for neoplasia in patients with augmented bladders may be of low utility given the low prevalence, the advanced stage at presentation, and the fast growth of tumors (meaning that many develop and spread during screening intervals) (65), and screening is unlikely to be cost-effective $(65,75)$. Figure 1 shows the endoscopic appearance of a neoplasm in bladder augmented with colon. Clinical follow-up of all patients with neurogenic bladder on at least an annual basis is still encouraged as significant changes in the health of these patients may be silent or present with only subtle findings. Husmann's group encourages annual evaluation of renal function, sonographic upper tract assessment, urinalysis, and other tests as directed by patient-specific risk factors (e.g., Vitamin B12 levels). Endoscopy is reserved for patients with increasing upper tract dilatation, recurrent urinary tract infections (four or more over one year), hematuria (gross or $>50 \mathrm{RBC} / \mathrm{hpf}$ ), persistent perineal or pelvic pain, and abnormal radiographic imaging. Additionally, patients should have periodic endoscopy of the augmented reservoir, aligned with contemporary recommendations for colon cancer screening in the general population (currently, every 10 years for patients aged $50-75$ years with earlier or more frequent testing in patients with predisposing syndromes and other risk factors) $(76,78)$.

\section{Risks associated with suprapubic tubes}

Urinary diversion with suprapubic tubes has also been associated with neoplastic transformation. Historically, longterm indwelling catheters carry a $10 \%$ risk of developing bladder cancer (Figures 2 and 3; typically squamous cell carcinoma), although like augmentation cystoplasty, these tumors tend to present after a decade or more of sustained drainage (79). More recent work has suggested that the risk attributable to suprapubic tube diversion may be lower (80); because suprapubic tube diversion was extremely common in the past, suprapubic tube drainage may have been confounded with the presence of abnormal bladder tissue predisposing to increase neoplastic risk, since clean intermittent catheterization has been a common practice for less than 50 years (81). The presence of a suprapubic 


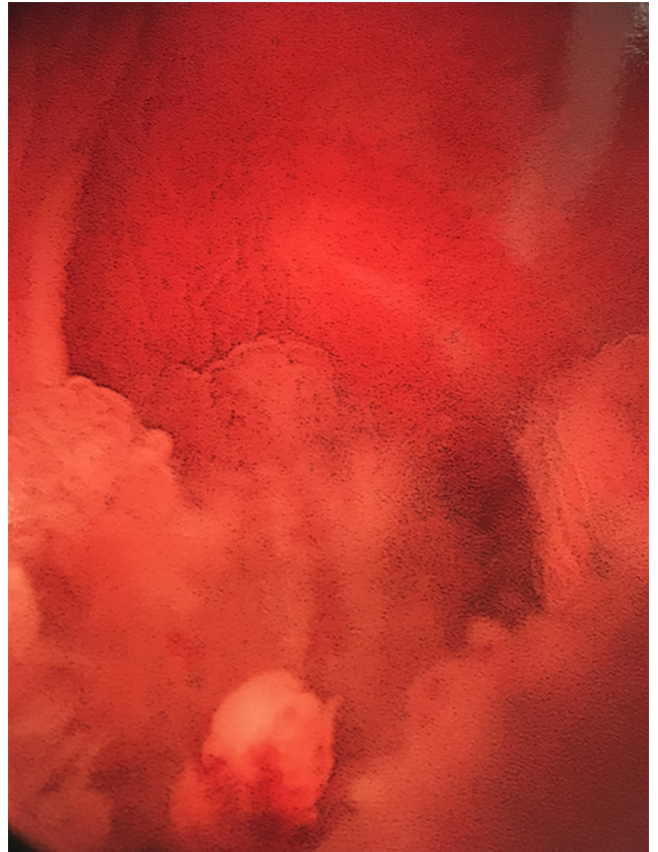

Figure 2 Endoscopic appearance of squamous cell carcinoma in a patient with longstanding suprapubic tube drainage. Image courtesy of Jane L. Miller, MD.

tube or other chronic bladder irritant (e.g., bladder stones) has been associated with histologic changes in the bladder mucosa or along the suprapubic tract, some of which may favor the development of neoplasia (82). Isolated involvement of the suprapubic tract may occur without cancer in the bladder $(83,84)$. Mucinous adenocarcinomas have also been reported in patients with indwelling catheters but are less common than squamous cell carcinomas (85) Although bladder drainage with an indwelling urethral catheter is less common than with suprapubic tubes, risks are likely similar in these patients. Despite the potential risk for neoplastic transformation in the bladders of patients with indwelling catheters, annual screening has not been found cost- or clinically-effective in the early detection of bladder cancers (86).

\section{Risks associated with abnormal bladder function}

The majority of bladder cancers reported in patients with neurogenic bladder are associated with lower urinary tract reconstruction and/or chronic indwelling catheters; however, underlying bladder dysfunction may be an independent risk factor for the development of neoplasia. Husmann reported a $2.5 \%$ cumulative incidence of bladder

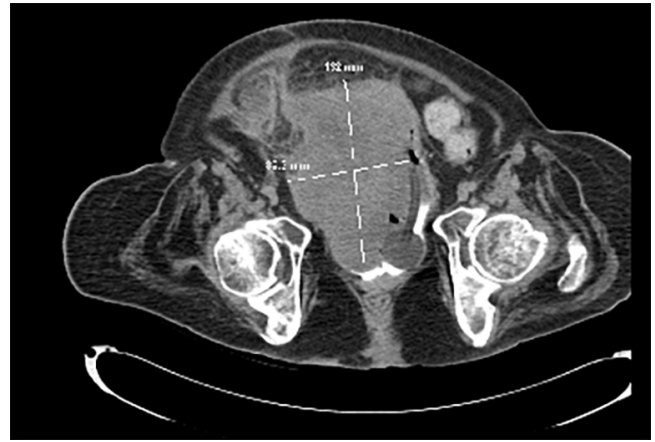

Figure 3 Radiographic appearance of neoplasm in a patient with longstanding suprapubic tube drainage. Image courtesy of Jonathan Wright, MD, MS.

cancer in patients with a neurogenic bladder but without augmentation cystoplasty (65), while Kalisvaart et al. found that over half of adult patients with spinal cord injury who developed bladder cancer did so in the absence of augmentation cystoplasty or of indwelling bladder catheter (80). A retrospective review of 446 patients with spina bifida treated at a single Spanish institution found a $2.2 \%$ cumulative incidence of bladder cancer; of these ten patients, two were managed with timed voiding, two with indwelling bladder catheters, one with a urinary diversion, and the remainder with CIC (87). Nine of the ten patients presented with locally extensive (T3) disease; $80 \%$ died within the first year with a median survival of four months after diagnosis. In contrast, the annual incidence of bladder cancer in the general population between 1999 and 2016 was orders of magnitude lower, ranging from 19.9 to 22.1 cases per 100,000 population, and consists largely of organconfined, low grade transitional cell carcinomas (88).

While the baseline risk of bladder cancer in myelomeningocele patients is not well quantified, numerous studies have investigated the development of bladder cancer in patients following spinal cord injury. In this population, cancer diagnoses are often made a decade or more after the injury. Although the precise etiologic and contributory factors have not been identified, prolonged urine dwell times, incomplete bladder emptying, chronic irritation (e.g., calculi, infections, indwelling catheters), and abnormal immune response have all been implicated $(89,90)$. Whether chronic bacteriuria in the absence of infection confers an increased risk of neoplasia is less clear. Smoking, which is a known risk factor for the development of bladder cancer, may be less prevalent in patients with spina bifida than in the general population or patients with spinal cord injuries (91); 
thus, the similarly elevated rates of bladder cancer in patients with spinal cord injury and spina bifida compared to the general population may reflect intrinsic bladder abnormalities that are not potentiated by tobacco exposure.

\section{Conclusions}

Owing to improved care in childhood, an adult population with spinal dysraphism has emerged and requires specialized urologic care and cancer screening. Patients with spinal dysraphism are exposed to numerous radiographic studies throughout their life-it is important to acknowledge that ionizing radiation is a known risk factor for development of malignancy. Clinicians caring for patients with spina bifida throughout the lifespan should be familiar with screening recommendations and factors that increase risk of malignancy in the lower urinary tract as well as systemically.

\section{Acknowledgments}

Funding: None.

\section{Footnote}

Provenance and Peer Review: This article was commissioned by the Guest Editors (John Wiener, Jonathan Routh and Nicholas Cost) for the series "Pediatric Urologic Malignancies" published in Translational Andrology and Urology. The article was sent for external peer review organized by the Guest Editors and the editorial office.

Conflicts of Interest: All authors have completed the ICMJE uniform disclosure form (available at http://dx.doi. org/10.21037/tau-19-771). The series "Pediatric Urologic Malignancies" was commissioned by the editorial office without any funding or sponsorship. The authors have no other conflicts of interest to declare.

Ethical Statement: The authors are accountable for all aspects of the work in ensuring that questions related to the accuracy or integrity of any part of the work are appropriately investigated and resolved.

Open Access Statement: This is an Open Access article distributed in accordance with the Creative Commons Attribution-NonCommercial-NoDerivs 4.0 International License (CC BY-NC-ND 4.0), which permits the noncommercial replication and distribution of the article with the strict proviso that no changes or edits are made and the original work is properly cited (including links to both the formal publication through the relevant DOI and the license). See: https://creativecommons.org/licenses/by-nc-nd/4.0/.

\section{References}

1. Parker SE, Mai CT, Canfield MA, et al. National Birth Defects Prevention Network. Updated National Birth Prevalence estimates for selected birth defects in the United States, 2004-2006. Birth Defects Res A Clin Mol Teratol 2010;88:1008-16.

2. Honein MA, Paulozzi LJ, Mathews TJ, et al. Impact of folic acid fortification of the US food supply on the occurrence of neural tube defects. JAMA 2001;285:2981-6.

3. Williams LJ, Rasmussen SA, Flores A, et al. Decline in the prevalence of spina bifida and anencephaly by race/ ethnicity: 1995-2002. Pediatrics 2005;116:580-6.

4. Oakeshott P, Hunt GM, Poulton A, et al. Expectation of life and unexpected death in open spina bifida: a 40-year complete, non-selective, longitudinal cohort study. Dev Med Child Neurol 2010;52:749-53.

5. Kancherla V, Druschel CM, Oakley GP. Population based study to determine mortality in spina bifida: New York State congenital malformations registry, 1983 to 2006. Birth Defects Res A Clin Mol Teratol 2014;100:563-75.

6. Lloyd JC, Wiener JS, Gargollo PC, et al. Contemporary epidemiological trends in complex congenital genitourinary anomalies. J Urol 2013;190:1590-5.

7. Sandler AD. Children with spina bifida: key clinical issues. Pediatr Clin North Am 2010;57:879-92.

8. Mitchell LE, Adzick NS, Melchionne J, et al. Spina bifida. Lancet 2004;364:1885-95.

9. Dicianno BE, Sherman A, Roehmer C, et al. Comorbidities associated with early mortality in adults with spina bifida. Am J Phys Med Rehabil 2018;97:861-5.

10. Liptak GS, Robinson LM, Davidson PW, et al. Life course health and healthcare utilization among adults with spina bifida. Dev Med Child Neurol. 2016;58:714-20.

11. Ouyang L, Grosse SD, Armour BS, et al. Health care expenditures of children and adults with spina bifida in a privately insured U.S. population. Birth Defects Res A Clin Mol Teratol 2007;79:552-8.

12. McDonnell GV, McCann JP. Issues of medical management in adults with spina bifida. Childs Nerv Syst 2000;16:222-7.

13. Binks JA, Barden WS, Burke TA, et al. What do we really know about the transition to adult-centered health care? 
A focus on cerebral palsy and spina bifida. Arch Phys Med Rehabil 2007;88:1064-73.

14. Malakounides G, Lee F, Murphy F, et al. Single centre experience: long term outcomes in spina bifida patients. J Pediatr Urol 2013;9:585-9.

15. Dicanno BE, Wilson R. Hospitalizations of adults with spina bifida and congenital spinal cord anomalies. Arch Phys Med Rehabil 2010;91:529-35.

16. Kinsman SL, Doehring MC. The cost of preventable conditions in adults with spina bifida. Eur J Pediatr Surg 1996;6:17-20.

17. Webb TS. Medical care of adults with spina bifida. J Ped Rehab Med 2009;2-11.

18. Liptak GS, Garver K, Dosa NP. Spina bifida grown up. J Dev Behav Pediatr 2013;34:206-15.

19. Mukherjee S, Pasulka J. Care for adults with spina bifida: current state and future directions. Top Spinal Cord Inj Rehabil 2017;23:155-67.

20. Young NL, Steele C, Fehlings D, et al. Use of health care among adults with chronic and complex physical disabilities of childhood. Disabil Rehabil 2005;27:1455-60.

21. Ramirez A, Garmer GC, Grand D, et al. Disability and preventative cancer screening: results from 2001 California Health Interview Survey. Am J Public Health 2005;95:2057-64.

22. De Pergola G, Silvestris F. Obesity as a major risk factor for cancer. J Obes. 2013;2013:291546.

23. Liu JS, Dong C, Vo AX, et al, Obesity and anthropometry in spina bifida: What is the best measure. J Spinal Cord Med 2018;41:55-62.

24. Chang CK, Hayes RD, Broadbent MT, et al. A cohort study on mental disorders, stage of cancer at diagnosis and subsequent survival. BMJ Open 2014;4:e004295.

25. Alimi Y, Iwanaga J, Osouian RJ, et al. Intelligence Quotient in Patients with Myelomeningocele: A review. Cureus 2018;10:e3137.

26. Shepard CL, Doerge EJ, Eickenmeyer AB, et al. Ambulatory care use among patients with spina bifida: change in care from childhood to adulthood. J Urol 2018;199:1050-5.

27. Ferrara P, Rossodivita A, Ruggiero A, et al. Cryptorchidism associated with meningomyelocele. J Paediatr Child Health 1998;34:44-6.

28. Wiener JS, Frimberger DC, Wood H. Spina bifida health-care guidelines for men's health. Urology 2018;116:218-26.

29. Kolon TF, Herndon CD, Baker LA, et al. Evaluation and treatment of cryptorchidism: AUA Guideline. J Urol
2014;192:337-45.

30. Johnston AW, Wolf S, Alkazemi MH. Patterns of inpatient care for prostate cancer in men with spina bifida. Disabil Health J 2020;13:100866.

31. Smith RA, Andrews KS, Brooks D, et al. Cancer screening in the United States, 2018: a review of current American Cancer Society guidelines and current issues in cancer screening. CA Cancer J Clin 2018;68:297-316.

32. Carter HB, Albertson PC, Barry MJ, et al. Early detection of prostate cancer: AUA Guideline. J Urol 2013;190:419-26.

33. Ristau BT, Alloway M, Cendo D, et al. Free-hand transperineal prostate biopsy provides acceptable cancer detection and minimizes risk of infection: evolving experience with a 10 -sector template. Urol Oncol 2018;36:528.e15-528.e20.

34. Torricelli FC, Lucon M, Vicentini F, et al. PSA levels in men with spinal cord injury and intermittent catheterization. NeuroUrol Urodyn 2011;30:1522-4.

35. Scott PA Sr, Perkash I, Mode D. Prostate Cancer diagnosed in spinal cord-injured patients is more commonly advanced stage than in able-bodied patients. Urology 2004;63:509-12.

36. Hoy NY, Metcalfe P. Complications following breast cancer therapy in the adult spina bifida population: a case report. Can Urol Assoc J 2013;7:E761-3.

37. Harper DM, DeMars LR. HPV vaccines- A review of the first decade. Gynecol Oncol 2017;146:196-204.

38. Streur CS, Schafer CL, Garcia VP, et al. "I don't know what I'm doing... I hope I'm not just an idiot." The need to train pediatric urologists to discuss sexual and reproductive health care with young women with spina bifida. J Sex Med 2018;15:1403-13.

39. Streur CS, Schafere CL, Garcia VP, et al. "If everyone else is having this talk with their doctor, why am I not having this talk with mine?" The experiences of sexuality and sexual health education of young women with spina bifida. J Sex Med 2019;16:853-9.

40. Neufeld JA, Klingbeil F, Bryen DN, et al. Adolescent sexuality and disability. Phys Med Rehabil Clin N Am 2002;13:857-73.

41. Peña-Fernández M, Abdulkader-Nallib I, NovoDomínguez A, et al. Vaginal tubulovillous adenoma: a clinicopathologic and molecular study with review of the literature. Int J Gynecol Pathol 2013;32:131-6.

42. Eradi B, Hamrick M, Bischoff A, et al. The role of a colon resection in combination with a Malone appendicostomy as part of a bowel management program for the treatment 
of fecal incontinence. J Pediatr Surg 2013;48:2296-300.

43. Davis R, Jones JS, Barocas DA. Diagnosis, evaluation and follow-up of asymptomatic microhematuria (AMH) in adults: AUA Guideline. J Urol 2012;188:2473-81.

44. Gaskill SJ, Marlin AE. Radiation exposure in the myelomeningocele population. Pediatr Neurosurg 1998;28:63-6.

45. Preston DL, Ron E, Tokuoka S, et al. Solid cancer incidence in atomic bomb survivors: 1958-1998. Radiat Res 2007;168:1-64.

46. Hall EJ. Lessons we have learned from our children: cancer risks from diagnostic radiology. Pediatr Radiol 2002;32:700-6.

47. Brody AS, Frush DP, Huda W, et al. Radiation risk to children from computed tomography. Pediatrics 2007;120:677-82.

48. Pearce MS, Salotti JA, Little MP, et al. Radiation exposure from CT scans in childhood and subsequent risk of leukaemia and brain tumours: a retrospective cohort study. Lancet 2012;380:499-505.

49. van Aalst J, Jeukens CR, Vles JS, et al. Diagnostic radiation exposure in children with spinal dysraphism: an estimation of the cumulative effective dose in a cohort of 135 children from The Netherlands. Arch Dis Child 2013;98:680-5.

50. Smookler G, Deavenport-Saman A. Retrospective study of cumulative diagnostic radiation exposure during childhood in patients with spina bifida. Disabil Health J 2015;8:642-5.

51. ALARA: as defined in title 10, section 20.1003, of the Code of Federal Regulations (10 CFR 20.1003). US Nuclear Regulatory Commission. Available online: http:// www.nrc.gov/reading-rm/basic-ref/glossary/alara.html. Accessed November 2, 2019.

52. Alliance for Pediatric Radiation in Imaging. Image gently. Available online: www.imagegently.org. Accessed November, 2019.

53. Leadbetter GW Jr, Zickerman P, Pierce E. Ureterosigmoidostomy and carcinoma of the colon. J Urol 1979;121:732-5.

54. Stewart M, Macrae FA, Williams CB. Neoplasia and ureterosigmoidostomy: a colonoscopy survey. Br J Surg 1982;69:414-6.

55. Zabbo A, Kay R. Ureterosigmoidostomy and bladder exstrophy: a long term followup. J Urol 1986;136:396-8.

56. Strachan JR, Woodhouse CR. Malignancy following ureterosigmoidostomy in patients with exstrophy. Br J Surg 1991;78:1216-8.

57. Cancer Stat Facts: Colorectal Cancer. Available online: https://seer.cancer.gov/statfacts/html/colorect.html. Accessed November 10, 2019.

58. Kälble T, Tricker AR, Möhring K, et al. The role of nitrate, nitrite and $\mathrm{N}$-nitrosamines in carcinogenesis of colon tumors following ureterosigmoidostomy. Urol Res 1990;18:123-9.

59. Hanna MK, Bassiouny I. Challenges in salvaging urinary continence following failed bladder exstrophy repair in a developing country. J Pediatr Urol 2017;13:270.e1-5.

60. Atta MA, Youssif TA, Boules GF, et al. Detubularized isolated ureterosigmoidostomy (Atta pouch): manometric and radiological studies in a sample of patients. Arab J Urol 2014;12:197-203.

61. Woodhouse CR; British Society for Gastroenterology; Association of Coloproctology for Great Britain and Ireland. Guidelines for monitoring of patients with ureterosigmoidostomy. Gut 2002;51 Suppl 5:V15-6.

62. Loeser A, Neumann M, Kocot A, et al. Serum carcinoembryonic antigen (CEA) and its possible use as tumor marker for secondary tumors in urinary intestinal reservoirs. Urol Oncol 2013;31:644-8.

63. de Freitas Filho LG, Carnevale J, Leão JQ, et al. Gastrocystoplasty and chronic renal failure: an acid-base metabolism study. J Urol 2001;166:251-4.

64. Rove KO, Husmann DA, Wilcox DT, et al. Systematic review of bladder cancer outcomes in patients with spina bifida. J Pediatr Urol 2017;13:456.e1-9.

65. Husmann DA. Mortality following augmentation cystoplasty: A transitional urologist's viewpoint. J Pediatr Urol 2017;13:358-64.

66. Vemulakonda VM, Lendvay TS, Shnorhavorian M, et al. Metastatic adenocarcinoma after augmentation gastrocystoplasty. J Urol 2008;179:1094-6.

67. Boissier R, Di Crocco E, Faure A, et al. What is the outcome of pediatric gastrocystoplasty when the patients reach adulthood? BJU Int 2016;118:980-6.

68. Castellan M, Gosalbez R, Bar-Yosef Y, et al. Complications after use of gastric segments for lower urinary tract reconstruction. J Urol 2012;187:1823-7.

69. Casey JT, Chan KH, Hasegawa Y, et al. Long-term followup of composite bladder augmentation incorporating stomach in a multi-institutional cohort of patients with cloacal exstrophy. J Pediatr Urol 2017;13:43.e1-6.

70. Gitlin JS, Wu XR, Sun TT, et al. New concepts of histological changes in experimental augmentation cystoplasty: insights into the development of neoplastic transformation at the enterovesical and gastrovesical anastomosis. J Urol 1999;162:1096-100. 
71. Little JS Jr, Klee LW, Hoover DM, et al. Long-term histopathological changes observed in rats subjected to augmentation cystoplasty. J Urol 1994;152:720-4.

72. Mammadov E, Dervisoglu S, Elicevik M, et al. Transition to adulthood with a bladder augmentation: histopathologic concerns. Int Braz J Urol 2017;43:1152-9.

73. Santiago-Lastra Y, Cameron AP. Urologic cancer surveillance in patients with bladder augmentation. Curr Bladder Dysfu Rep 2015. doi: 10.1007/s11884-015-0330-7.

74. Reddy BN, Subhash M, Pilichowska M, et al. Primary squamous cell carcinoma arising from a cutaneous ureterovesical stoma (modified Mitrofanoff): case report and review of literature. Urology 2017;99:225-7.

75. Kokorowski PJ, Routh JC, Borer JG, et al. Screening for malignancy after augmentation cystoplasty in children with spina bifida: a decision analysis. J Urol 2011;186:1437-43.

76. Higuchi TT, Fox HA, Husmann DA. Annual endoscopy and urine cytology for the surveillance of bladder tumors after enterocystoplasty for congenital bladder anomalies. J Urol 2011;186:1791-5.

77. Szymanski KM, Misseri R, Whittam B, et al. Additional surgeries after bladder augmentation in patients with spina bifida in the 21st century. J Urol 2020;203:1207-13.

78. What Should I Know About Screening? Accessed March 11, 2020. Available online: https://www.cdc.gov/cancer/ colorectal/basic_info/screening/index.htm

79. Locke JR, Hill DE, Walzer Y. Incidence of squamous cell carcinoma in patients with long-term catheter drainage. $\mathrm{J}$ Urol 1985;133:1034-5.

80. Kalisvaart JF, Katsumi HK, Ronningen LD, et al. Bladder cancer in spinal cord injury patients. Spinal Cord 2010;48:257-61.

81. Lapides J, Diokno AC, Silber SJ, et al. Clean, intermittent self-catheterization in the treatment of urinary tract

Cite this article as: Arlen AM, Dudley AG, Kieran K. Association of spina bifida with cancer. Transl Androl Urol 2020;9(5):2358-2369. doi:10.21037/tau-19-771 disease. J Urol 1972;107:458-61.

82. Delnay KM, Stonehill WH, Goldman H, et al. Bladder histological changes associated with chronic indwelling urinary catheter. J Urol 1999;161:1106-8.

83. Stroumbakis N, Choudhury MS, Hernandez-Graulau JM. Squamous cell carcinoma arising from suprapubic cystotomy site without bladder involvement. Urology 1993;41:568-70.

84. Schaafsma RJ, Delaere KP, Theunissen PH. Squamous cell carcinoma of suprapubic cystostomy tract without bladder involvement. Spinal Cord 1999;37:373-4.

85. Bauman TM, Potretzke TA, Potretzke AM, et al. Mucinous adenocarcinoma of the bladder associated with long term suprapubic tube: a case report. BMC Urol 2015;15:119.

86. Yang CC, Clowers DE. Screening cystoscopy in chronically catheterized spinal cord injury patients. Spinal Cord 1999;37:204-7.

87. Melendez M, Maroto A, Illescas T, et al. Bladder cancer in patients with spina bifida: observation from an adult clinic. Spinal Cord Series Cases 2018;4:27.

88. United States Cancer Statistics: Data Visualizations. Available online: https://gis.cdc.gov/Cancer/USCS/ DataViz.html. Accessed November 6, 2019.

89. Welk B, McIntyre A, Teasell R, et al. Bladder cancer in individuals with spinal cord injuries. Spinal Cord 2013;51:516-21.

90. El-Mosalamy H, Salman TM, Ashmawey AM, et al. Role of chronic E. coli infection in the process of bladder cancer- an experimental study. Infect Agent Cancer 2012;7:19.

91. Soe MM, Swanson ME, Bolen JC, et al. Health risk behaviors among young adults with spina bifida. Dev Med Child Neurol 2012;54:1057-64. 